This item was submitted to Loughborough's Research Repository by the author.

Items in Figshare are protected by copyright, with all rights reserved, unless otherwise indicated.

\title{
Advising without personalising: How a helpline may satisfy callers without giving medical advice beyond its remit
}

PLEASE CITE THE PUBLISHED VERSION

https://doi.org/10.1111/1467-9566.13088

PUBLISHER

Wiley

VERSION

AM (Accepted Manuscript)

\section{PUBLISHER STATEMENT}

This is the peer reviewed version of the following article: ANTAKI, C. and BLOCH, S., 2020. Advising without personalising: how a helpline may satisfy callers without giving medical advice beyond its remit. Sociology of Health and IIIness, 42 (5), pp.1202-1219, which has been published in final form at https://doi.org/10.1111/1467-9566.13088. This article may be used for non-commercial purposes in accordance with Wiley Terms and Conditions for Use of Self-Archived Versions.

\section{LICENCE}

CC BY-NC-ND 4.0

\section{REPOSITORY RECORD}

Antaki, Charles, and Steven Bloch. 2020. "Advising Without Personalising: How a Helpline May Satisfy Callers Without Giving Medical Advice Beyond Its Remit”. Loughborough University. https://hdl.handle.net/2134/11949870.v1. 

Advising without personalising: How a helpline may satisfy callers without giving medical
advice beyond its remit

\author{
Charles Antaki \\ School of Social Sciences and Humanities \\ Loughborough University \\ Loughborough LE11 3TU \\ UK \\ c.antaki@Lboro.ac.uk \\ Steven Bloch \\ Department of Language and Cognition, \\ University College London, \\ Chandler House, \\ 2 Wakefield Street, \\ London WC1N 1PF, \\ UK. \\ s.bloch@ucl.ac.uk
}

Accepted March 2020 for publication in Sociology of Health and Illness

\title{
Abstract
}

Callers to telephone helplines often seek advice beyond the authorisation of those staffing the service. On health-helplines, this poses a problem to the call-taker. How do they manage the dilemma between, on the one hand, exceeding their competence and authority to give medical advice, and, on the other, leaving the caller unsatisfied with the service? We offer a framework in which to set newly identified practices along with those identified in previous studies. Using a set of calls to a medical help-line run by Parkinson's UK, we show that the call-taker manages the problem by (a) only suggesting courses of action highly marked for impersonality or contingency (displaying a "low deontic stance", Stevanovic and Peräkylä, 2012), and (b) limiting the interactional risks of tailoring the advice to callers' personal circumstances. We show how our suggested framework of "advising without personalising" may guide research into the difficult job of delivering advice where the service-provider must observe a limit on what they can say.

\section{Keywords}

Parkinson's disease, telephone helpines, advice, conversation analysis, specialist nurse

\section{Introduction}

Telephone helplines are channels that commercial organisations, charities, and government agencies use to support customers, clients, patients and other service-users. The edited volume Calling for Help (Baker, Emmison, \& Firth, 2005) was a landmark in bringing together research on helplines from a perspective which analysed the details of how callers and calltakers managed their interaction. Since then, as Bloch and Leydon (2019) report, interactional research has focussed on structural matters (especially how calls are opened, 
e.g. Danby, Baker and Emmison (2005) and closed, (e.g. Woods et al, 2015); how troubles are told and received (e.g. Bloch and Antaki, 2019); how callers express emotion (e.g. Hepburn and Potter, 2007), how call-takers respond (e.g. Stommel \& Te Molder, 2018); and how advice is solicited, given, and received (e.g. Butler, Potter, Danby, Emmison, \& Hepburn, 2010). There is, however, something useful, but so far missing: a framework to study how advice is not given.

\section{Not giving advice}

Our interest in this article is with the many helplines set up by organisations with a medical remit (for example, those which offer information or help for any health problem, or for a given chronic condition such as Parkinson's disease). They may be staffed by personnel who are medically qualified (for example, the UK's National Health Service "111" service (NHS, no date), or who have no medical training (and perform only a referral service; for example, the UK's National Society for the Prevention of Cruelty to Children (NSPCC, no date), with all shades of expertise in between. The services may be purely informational, or may develop into urgent, expert medical advice; and, again, all shades of service in between. In all cases, the call-taker faces the sometimes challenging task of ascertaining what service the caller requires and whether the call-taker can provide it; dispensing it satisfactorily; and ending the call ready for the next one. Our specific focus is on one, especially difficult kind of helpline: that where the call-taker receives queries about medical matters, but is prevented (by institutional injunction, or lack of adequate training, or both) to give specific medical advice as such. How do they work?

To begin answering that question, it's worth contrasting such helplines with medical helplines which do give advice, and are explicitly meant to do so: for example, a poison emergency helpline will be staffed by a pharmacist explicitly mandated to give advice about what the caller has ingested or been exposed to (see Landqvist 2013 for an analysis of such direct advice). The ones we have in our sights are offered by agencies which include medical services, but whose telephone helpline operatives, even if qualified, are institutionally mandated not to diagnose, treat or advise. They may offer emotional support, answer queries, give information, and so on; but they may not provide medical advice specific to the caller's problem. In the UK, the Royal College of Nursing sets out specific guidelines for practitioners working on that kind of telephone helpline for people with long term conditions (Royal College of Nursing 2006). They warn that call-takers should be circumspect in what help or advice they offer which, as they point out, must be limited "if the nurse does not have access to the patient records at the time of the call" (2006, p 16), let alone not able to examine them physically. While such guidelines are useful to some degree, they are far from comprehensive. We need to see how call-takers actually abide by the injunction.

\section{The interactional management of advice}

In previous discussions of how the helpline call-taker solves their dilemma of advice versus care, attention has been perhaps too squarely on the success with which the call-taker's practices managed to keep on the right side of the medical-institutional injunction not to advise. That has meant less importance has been attached to how the call-taker manages 
the caller's expectations, an arguably equally important (and certainly no less challenging) aspect of their job. So we add to our analysis the novel consideration of how the call-taker's practices solve that interactional problem, as well as the medical-institutional one.

\section{Data}

Our data come from recordings from three sources. One is a set of helpline calls that we have full access to, and two are excerpts published in the two extant studies of helplines staffed by providers who cannot give medical advice - Butler et al (2009) and Shaw and Kitzinger (2013). The helpline that Butler et al analysed was staffed by "experienced paid nurses with general nursing qualifications and midwifery and / or child health postgraduate certificates" (2009, p 819). They are not meant to offer medical advice, although callers do make such requests. As one call-taker says, this is the Child Health Line. So it's not a medical help line. Nevertheless the search for, and the provision of, some kind of advice is a very live matter: the caller in that exchange goes on to say I was wondering about projectile vomiting and the topic is accepted for discussion (2009, $\mathrm{p}$ 827). The Home Birth helpline, according to Shaw and Kitzinger (2013, pp7-8) is "a UK-based, voluntary organisation ... offering support and information for women planning a home birth". Although the helpline is staffed at different times by a variety of call-takers, some of whom are medically qualified, the call-taker in the data published was not medically qualified (C. Kitzinger, personal communication). Again, the concern for what course of action to follow, and how to satisfy it, is very much a live matter to both caller and call-taker.

The data we have full access to, and which therefore form the bulk of the examples in this article, are calls to the Parkinson's UK helpline ${ }^{1}$. This helpline is not designed to offer medical diagnoses or prescribe interventions for this neurological disease, but staff may give information and support. Callers contact the telephone line with e.g. a medication query, a benefits query or a general Parkinson's health related question (for more detail on the service, see Bloch and Antaki, 2019). Calls that are requests for general information or more specific questions about social benefits, services, housing etc. are initially dealt with by nonmedically trained operators, not analysed in this article. Callers who present with a nonemergency medical problem or query are offered a call-back from a specialist nurse within 48 hours. Basic details are then recorded and transferred to one of the specialist nurses for action (these then are the calls we analyse here). All callers who gave initial verbal consent subsequently gave written consent. Recording protocols and ethics procedures were approved by the University College London Research Ethics Committees. The data examined here comprises audio-recorded telephone conversations between two specialist nurses and 30 callers - most $(n=22)$ are people with Parkinson's disease with the rest $(n=8)$ being close family members. Although the nurse has called the enquirer back, to keep the terms uniform with the other helplines we examine, we will refer to her as the "call-taker".

\section{Analysis}

\section{Preamble: what prompts the call-taker to respond to the caller's query}

\footnotetext{
${ }^{1}$ We have transcribed these according to the familiar conventions of conversation analysis based on Jefferson (2004), though without especial regard to non-lexical elements (as explored in Keevallik and Ogden, 2020, and reviewed in Dingemanse, 2020).
} 
Examination of the calls suggested that callers' reasons for using the service tended to be expressed as concerns about a recent development (for example, that the caller has begun to have problems with walking). There were no explicit requests for advice as such, echoing Leppänen's (1998) study of interactions between patients and their district nurses. Rather, the environment in which advice became relevant was when the caller described an untoward states of affairs, as did the mothers in Heritage and Sefi $(1992)^{2}$ but here more specifically, the call-taker held off until just that point at which the caller's account arrived at the personal consequences of that state of affairs (for example, .... And I find that this this disturbs my sleep to such an extent that it makes it bad for me during the day) ${ }^{3}$. In what follows, we shall identify how the call-taker deals with the problem from that point onwards. Our aim is to identify features of the call-takers' practice, over a range of medical help-line services, that allow the call taker to manage giving medical advice when they are required to not do so.

\section{Confirmation of practices seen elsewhere}

Before addressing new practices, it is worth confirming previous research on medical helplines where the call-taker is meant not to give advice: Butler et al, (2009), on a child health line, and Shaw and Kitzinger on a home birth helpline (Shaw \& Kitzinger, 2013). Butler et al (2009) report three practices used by their call-takers on the child health line: disavowal of the power to give advice; normalising the caller's problem; and deferring to the caller's parental authority (that is, encouraging the caller to use their own judgement as a parent familiar with the child's general health and habits). That third practice is very specific to the nature of their Child Health service data, and isn't relevant to the adult callers here (though we will return to it in the Discussion). Shaw and Kitzinger report on one call, with a focus on what they term the call-taker's 'problem solution' offered to the caller ${ }^{4}$. Although their analysis doesn't specifically address the practices of not giving advice there are, as we shall see, aspects of their call-taker's actions which are relevant to advice giving. Between them, then, we have the practices of: resisting giving advice at all, and respecifying the problem as 'normal' and not requiring any advice. Let us see if we can confirm these in our data, before moving on to new practices that appear in ours but not theirs.

\section{Direct resistance to giving advice}

The most obvious way not to give advice on the helpline would be to explicitly say that one can't. Butler at al (2009) give clear examples of the call-taker on a child health line explicitly disavowing the power to advise, as in this example:

\footnotetext{
${ }^{2}$ Heritage and Sefi recorded UK community health visitors on their visits to mothers, and among the things they found was that mothers tended not to request advice, but solicit it by describing something their baby had done which they cast as unusual in some way (eg not feeding normally, being untypically fractious etc.) ${ }^{3}$ This practice is more fully described in Bloch \& Antaki (2019)

${ }^{4}$ The call-taker at one point gives quite specific advice which is procedural, rather than medical as such (not to attend a hospital where the caller had had a poor experience, but to inform them in writing that she intends to have a home birth).
} 


\section{Example 1}

Butler et al (2009. p 823, part of Extract 2)

60 CT >yeah< $\mathrm{h}$ we're not allowed to give medical advice

61 so .h obviously .h you hav-.h see the doctor t- to

62 confirm $(0.2)$ to confirm thị:s.

In our Parkinson's corpus, the closest were examples which the call-taker denied, not that she could give advice as such, but that she could prescribe or diagnose a problem. This was relatively common in our data, and, notably, was often (as in the case reported by Butler et al above), prefaced by the evidential adverb obviously, as in these examples below. In example 1, we join the talk during the call-taker's response the the caller's concern that a given symptom might be athritis or a trapped nerve.

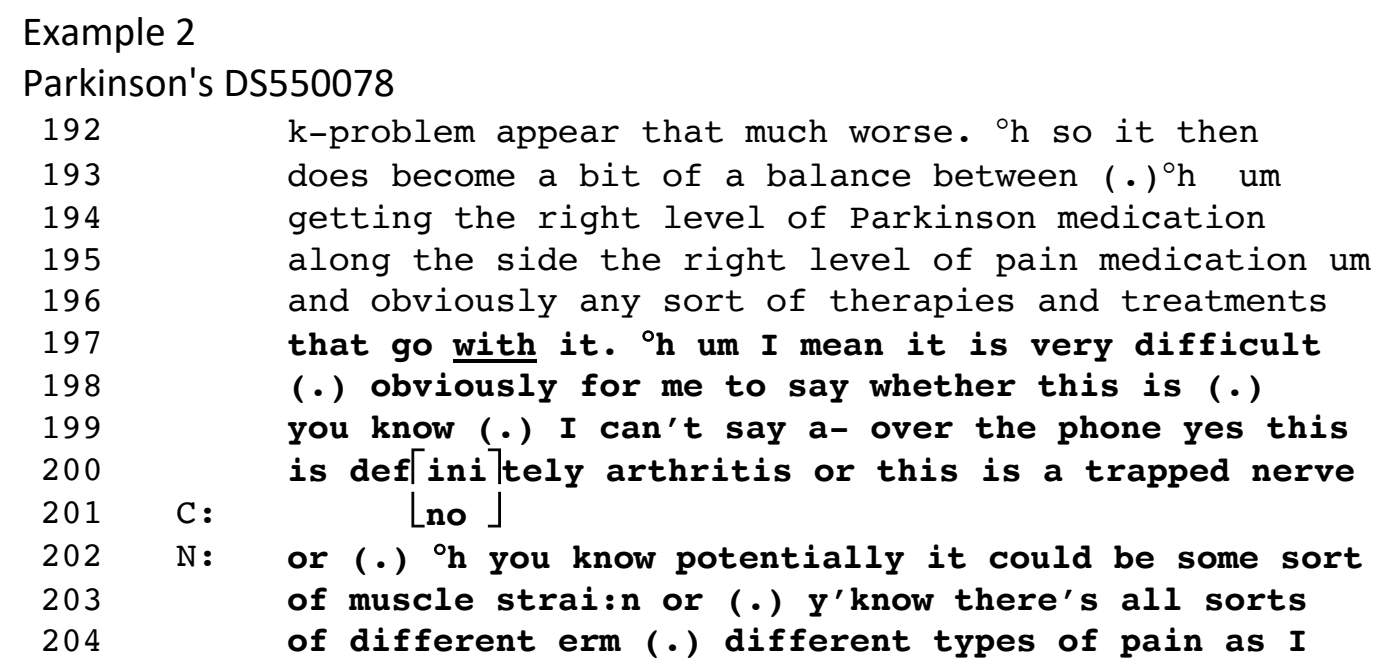

Note how the call-taker deploys some useful ambiguity in what sort of difficulty she is experiencing in lines 197 (her personal competence, or the institutional constraints she must observe?). Moreover, the difficulty will, she claims, be equally apparent to the caller. We shall see that obviously plays a significant part in how these disclaimers work, when we come to examine the interactional effects of the way the call takers design their turn.

Re-specifying a medical problem as something normal.

Butler et al (2009) report that the call-taker on a child-health telephone helpline could deal with a query by treating the reported condition as a merely normal part of the child's development. For example, a baby's vomiting was explained as a normal consequence of an immature digestive system (and so required no further course of action). In our data the call-taker has less leeway for such redefinition, given that the patient is already known to have a neurological disease with reasonably well recognised symptoms. But it was possible nevertheless for the call-taker to treat the symptoms reported as being, if not 'normal', then at least normal for this particular stage of the illness, and on that basis requiring no (further) course of action.

In the example, below, the caller is concerned about feeling hot and sweaty at night.

Example 3 


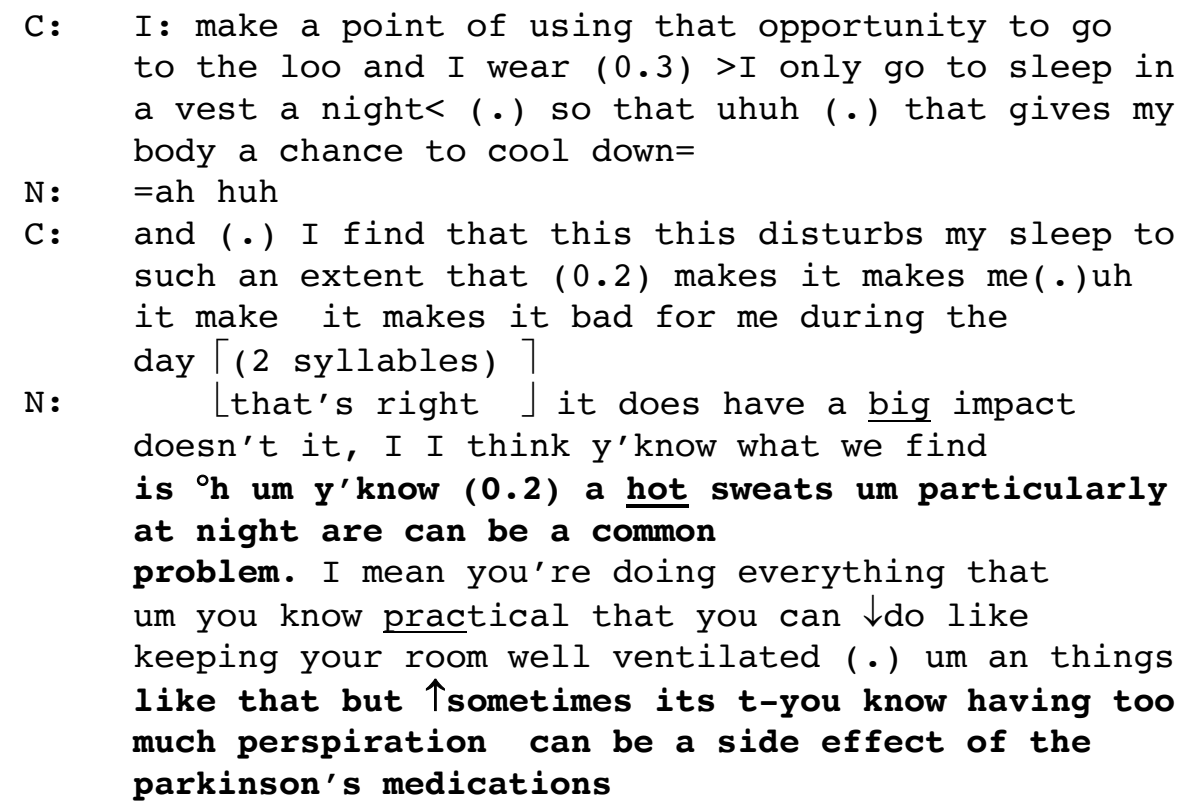

The call-taker converts the caller's worries (about possible overheating) from one that requires a novel course of action to one that would be explained (or explained away) as common side-effects of medication, requiring no further action.

\section{Novel practices: Managing advice by adopting a low deontic stance}

We now turn to features which extend what we know about advice giving from previous research in these limited-authority medical contexts. These new practices temper what Heritage and Sefi (1992), in their pioneering study of medical advice-giving, identified as the asymmetric nature of advice - that the advice-giver must have, or act as if they have, more expertise than the advice-receiver. We may put this asymmetry into the broader context of authority - what Stevanovic and Peräkylä (2012) identified as the degree to which the calltaker adopts a "deontic stance" in recommending, proposing or suggesting some course of action to another, or instructing, requiring or demanding that they carry it out. Clearly, as Stivers et al observe about medical consultations, "treatment recommendations embody epistemic and deontic authority both as a background to their production and as encoded in their design" (Stivers et al, 2018, p 1336). To give an example of a high deontic stance, consider the kind of unqualified imperative instructions that parents feel licenced to give their children, as analysed by Craven and Potter (2010): move along a little bit; don't be horrible; you need to be kind to your sister; and so on; or that support staff give to serviceusers with an intellectual disability (Antaki and Kent, 2012): turn the oven on ... turn the oven on, no, turn it on; you need to get a spoon; tip it up and put some orange in it; and so on. We shall see that the stance the call-takers adopt is very different. They take a very low deontic stance for the overwhelming majority of the courses of action suggested, and reserve a high deontic stance for only routine or already-established matters. We will deal with the majority first. 
We found that the call-taker marked their authority as being in some way diminished or constrained, and explicitly not designed to meet the close detail of the caller's situation.

They did so in three main ways:

a) by presenting information which was relevant to, or implied, a course of action (or a course of no action) without casting it as a course of action (Silverman and Peräkylä's familiar advice as information, 1990)

b) by marking the advice as contingent, with explicit if- then clauses and modal verbs (it may be /would be worth doing $X$, we would suggest, you might...); and

c) by presenting the advice as a matter of in-principle, impersonal, established procedure or course of action.

The institutional benefit of not-advising

Demurring from outright recommendation in the ways listed above abides by the professional injunction not to give advice without adequate medical evidence about the patient's specific situation. If the information is merely just that - information, not advice; if treatment is contingent on what may or may not be the case; and if it is being presented as an in-principle course of action, applicable to generic cases, then it is manifestly not offered as something accountable to this caller, in their specific situation. All of these are advising without advising - that is, they make available for receipt a course of action, without expressly telling the recipient to follow it.

The interactional benefit of setting an epistemic boundary

We shall also argue that there is a further interactional benefit to the call-taker of giving information, of putting things contingently, and appealing to general principles. This benefit hinges on what Heritage (2012) calls a person's epistemic status; that is, one's entitlement (or lack of it) to know about matters at issue in the exchange, due to one's expertise or experience. We shall see that the call-taker's professional status allows her to assert contingent or generic medical knowledge. That sets (or attempts to set) a boundary around the terms of the answer she is giving, with the caller's non-professional, anecdotal testimony left outside it. That makes it harder for the caller to issue personal-experience based challenges which would entail delays in the resolution of the call - although, as we shall see, such challenges are not impossible.

In the analysis below we shall analyse the formats by which advice is circumvented, and draw out their boundary-setting interactional advantage to the call-taker.

\section{a) Advice as information}

Communicating an implied course of action by (ostensibly) merely giving information has, since Silverman and Peräkylä's work on HIV/Aids counselling (Silverman and Peräkylä, 1990), been well documented in medical consultations (for example, by Garcia, 2012; Heritage and Lindström, 2012; and to one side of our medical-advice interests, Butler et al's 2015 study of child counsellors). There are abundant examples of advice-as-information in our corpus, of which the case below may stand as a typical example. (Note that the call-taker is also using other practices even in this short clip as well; we concentrate here only on lines 274-289). In 
example 4, we join the talk after the caller, in previous talk not shown, has expressed a worry about tremor and has raised the advisability of increasing the dosage of her medication.

Example 4

Parkinson's DS550100

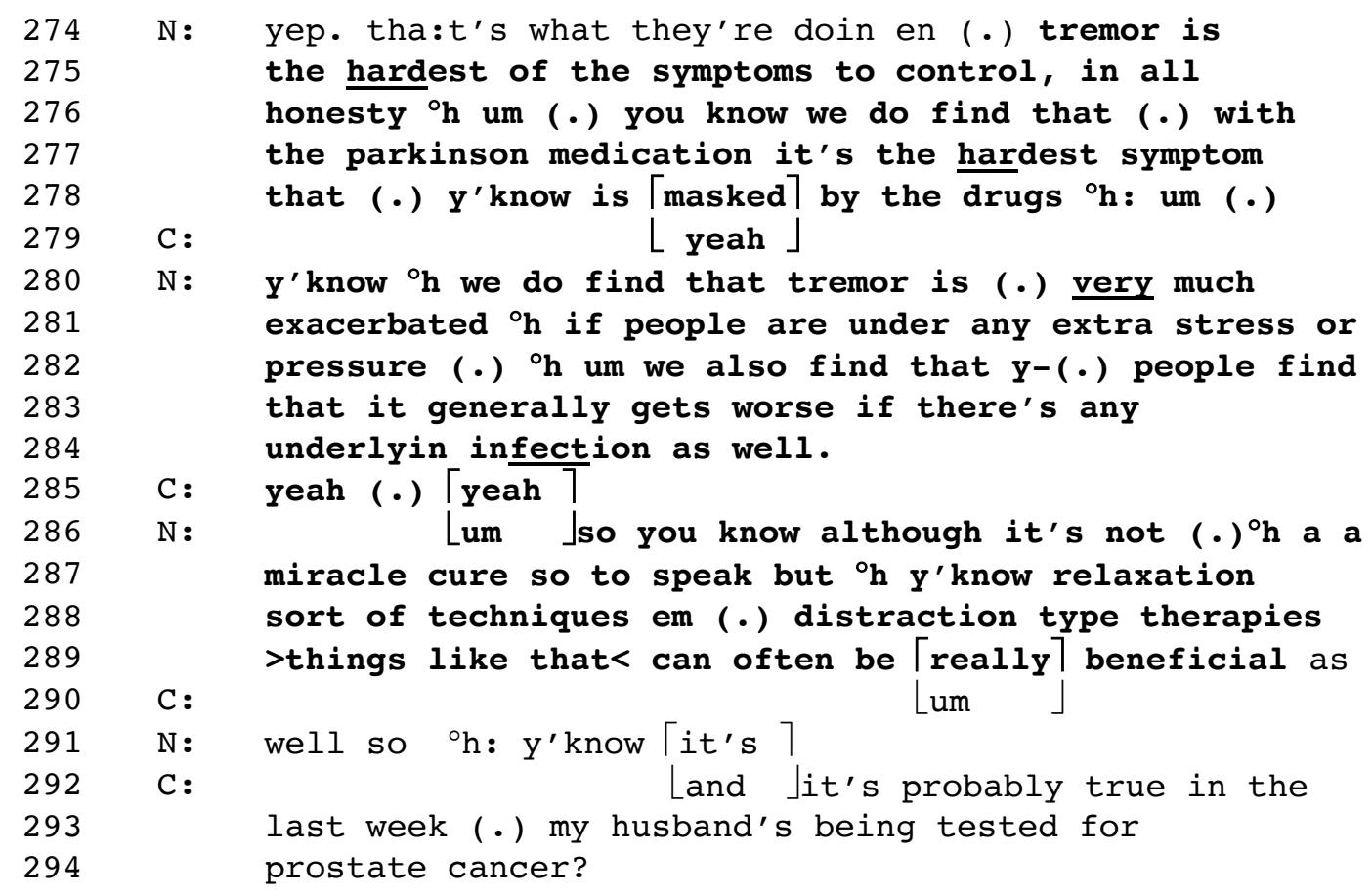

The call-taker could have advised the caller explicitly, with some formulation such as "that would not be a good idea; it's best if you keep on the same dosage" or equivalent; or she could have used one of the formulas we list below, which all imply a course of action. What is notable about what she does say, illustrating what Silverman and Peräkylä (1990) found in their study of HIV/AIDS counselling, is that it is a catalogue of, as it were, 'mere' information, from a generalised and impersonal "we" representing, presumably, the experts at Parkinson's UK. We might gloss it as an announcement of the fact that tremor is the hardest symptom to control; that stress exacerbates it; that it gets worse if there is an infection; that relaxation techniques can often help, and so on. None of these are courses of action (indeed they are "not a miracle cure") - they leave it entirely up to the caller to infer what any or all of them might suggest.

Managing advice as information in the Parkinson's case does not have the same range of virtues as it had for the HIV/Aids counsellor for whom it obviated the need to probe into intimate matters of their clients' sexual practices. But it does share the virtue of, as Peräkylä and Silverman observed, being non-controvertible; there is little danger of it being gainsaid by its recipient - the call-taker is simply describing the medical facts of the matter. We shall expand on this as we go along.

b) Contingent advice 
The call-taker had a number of ways of marking their advice as being contingent: if-then clauses and modal verbs were the most common. The call-taker may set the advice up as the consequence of an as-yet unknown contingency which is more properly a matter for the caller to know (and , implicitly, to act on). In the example below, contingency is the device to focus on, in the if-then format in lines 97-98 (though the call-taker uses other elements as well ${ }^{5}$ ).

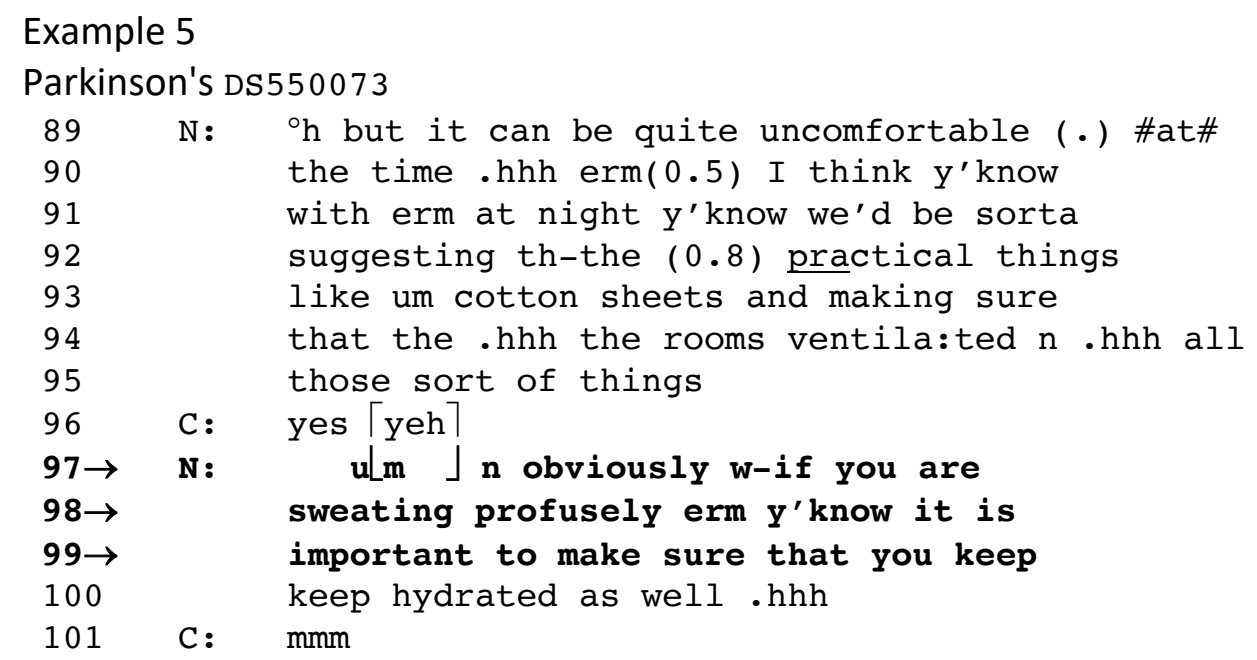

We shall have cause later to examine the use of "obviously", but let us concentrate here on the "if/then" construction. The content of the "if" clause above is epistemically available at first hand only to the caller: only they would know if they have been sweating at all, let alone profusely (a still more first-person, experiential, description). The copula "then" is implied, but the advice follows, in an impersonal formula of "it is important to make sure" which deletes both the issuer of the recommendation and also to whom it is directed (a device we shall come to in greater detail below). We can find the usage in Butler et al (2009) : if it's above thirty eight [degrees] then I'd probably need to maybe consider calling a doctor Butler et al 2009, $\mathrm{p}$ 825, data simplified). This if/then usage is visible even by call-takers on the now-defunct UK NHS Direct helpline, staffed by nurses who were explicitly meant to give advice (Greatbatch et al 2005), as here:

Example 6

Greatbatch et al p 808 Extract 2 (part)

$\begin{array}{lll}57 & \text { Nurse } & \text { Now if } \quad \text { [things } \\ 58 & \text { Caller } & \\ 59 & \text { Nurse } & \text { if things are not settling down } \\ 60 & \text { Caller } & \text { mhm: } \\ 61 & \text { Nurse } & \text { you know sort of after the weekend } \\ 62 & \text { Caller } & \text { yes } \\ 63 & \text { Nurse } & \text { then I'd pop back to see your doctor }\end{array}$

\footnotetext{
${ }^{5}$ In the extracts you may see the call-taker manage their advice by using more than one practice at a time. For example, the call-taker might present the advice as information, but also make it contingent on some currently unknown state of affairs. For the purposes of exposition, we shall under each heading concentrate only on one feature in a given extract, and reserve consideration of their combination till later in the paper.
} 
The point to stress in all these cases is that the call-taker has made the course of action entirely contingent on something that she does not know, but the caller does; that greatly diminishes the call-taker's deontic authority to tell them what to do.

Contingency can also be_signalled by using an existential sentence incorporating a modal auxiliary - for example it would be, it might be, and so on. To add to the low deontic weight of what they then go on to assert, the next clause can be phrased with an agentless participle - so it may be worth asking for the test to be redone, rather than it may be worth you asking for the test to be redone. In the example below, the call-taker's may casts the advice as being dependent on some as yet unknown contingency. Example 7 shows part of a long stretch of talk in which the call-taker is responding to the caller's concern about his wife, which he expresses (in an earlier stretch of talk) as "the main concern was what >I say about was was< what's happened recently with the memory and confusion you know" and also "she's been treated for depression". The call taker goes through a long account of how Parkinson-related chemical changes in the brain may cause depression and confusion, and that lithium treatment may exacerbate symptoms; that leads her on to explain (in the data below) that dosage levels have to be carefully calibrated with tests.

\section{Example 7}

Parkinson's DS550069

470 N: $\uparrow$ well: sometimes you know with these tests

471 erm $y^{\prime}$ know when you've got th-the jus-one

472 test done its very difficult for them to

473 have any sort of baseline. hhh so it may be

474 worth asking for the (.) test to be redone .hhh

475 Ter they may want ta $\rceil$ do (0.2) a more intensive

476 C: Lhave another one yeh 」

$477 \mathrm{~N}$ : test with her. hh so we've got a sort of

478 baseline sort of reading now from when th-

479 the nurse came out but. hh to $\lceil$ do a nother one

480

C :

Lright 」

In Example 7 above, the contingency is not about something the caller can know, but rather depends on the uncertainties of medical tests. Moreover, the course of action is presented as tentative and underspecified - the it may be worth asking format allows it to be unclear who is to do the asking. In Example 8 below, it is it would be worth having a chat.

\section{Example 8}

Parkinson's DS550069

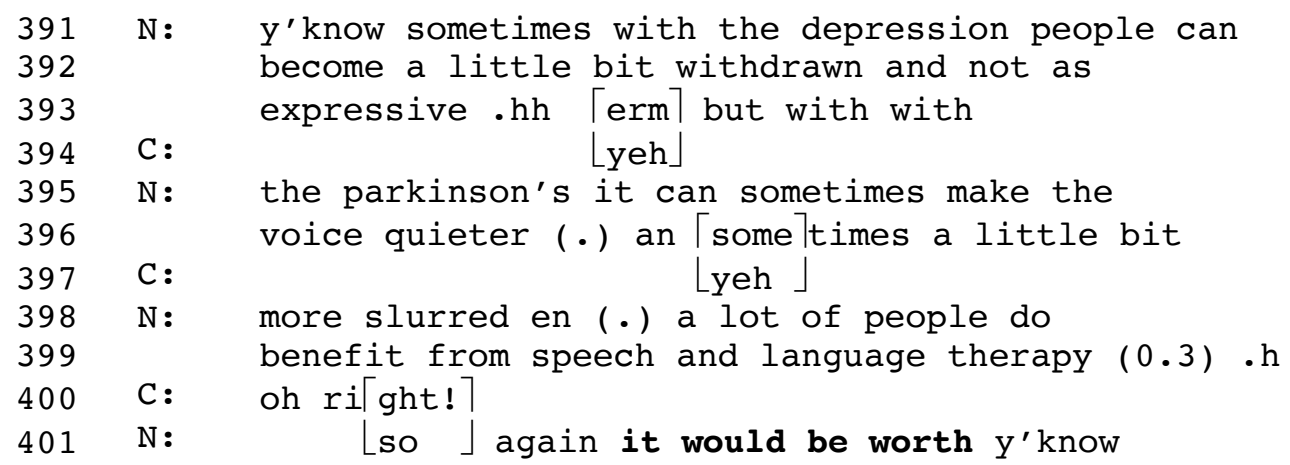




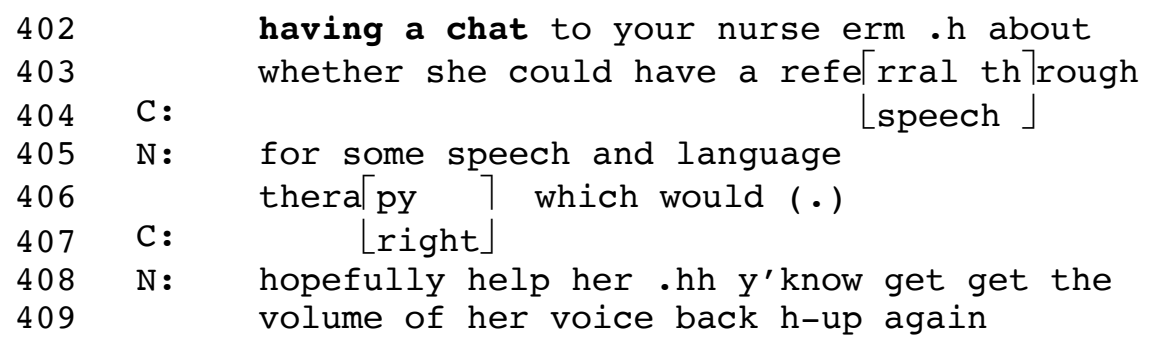

In Example 8 above, the impersonal would-be-worth formula is just one of a combination of devices: that the call-taker uses. She starts with general information about why a certain symptom might not be depression; then offers that a lot of people do benefit from a certain course of action; and finishes with the agentless it would be worth doing (a still less demanding) course of action, namely having a chat with your nurse. As well as the meeting the call-taker's overarching injunction not to give advice as such, contingency in the recommendation also has interactional value. If the "if" clause is unknown or unknowable (perhaps by being set in the future) then the call-taker is excused from having epistemic access to it. That makes it more difficult - though of course not impossible, as we shall see later - for the caller to engage with the call-taker in what would be (given the standing order not to give particular advice) futile prolongation of the call.

\section{c) Advice in principle}

The second common feature of the call-taker's advice-management in our data was their reference to standardly-known, in-principle courses of action (indeed, in a related observation about teacher training, Waring calls this kind of advice "depersonalised" Waring, 2017). This could be done by a variety of formulas, the three most prominent in our data being such epistemic markers as obviously, class-like generic descriptors such as one of those things, and passive, agentless verb forms such as in it does need to be looked at. We saw obviously being deployed in Example 8 above, and here it is again (line 33 below), prefacing the kind of modal verb formulation that we examined above. Just bore the start of Example 9, the call-taker has asked whether the caller's reported "feeling of lowness" started before she was given the diagnosis of Parkinson's; the caller has answered that "no it's it's hap- since I've started the medication actually".

\section{Example 9}

Parkinson's DS550081 (1.55)

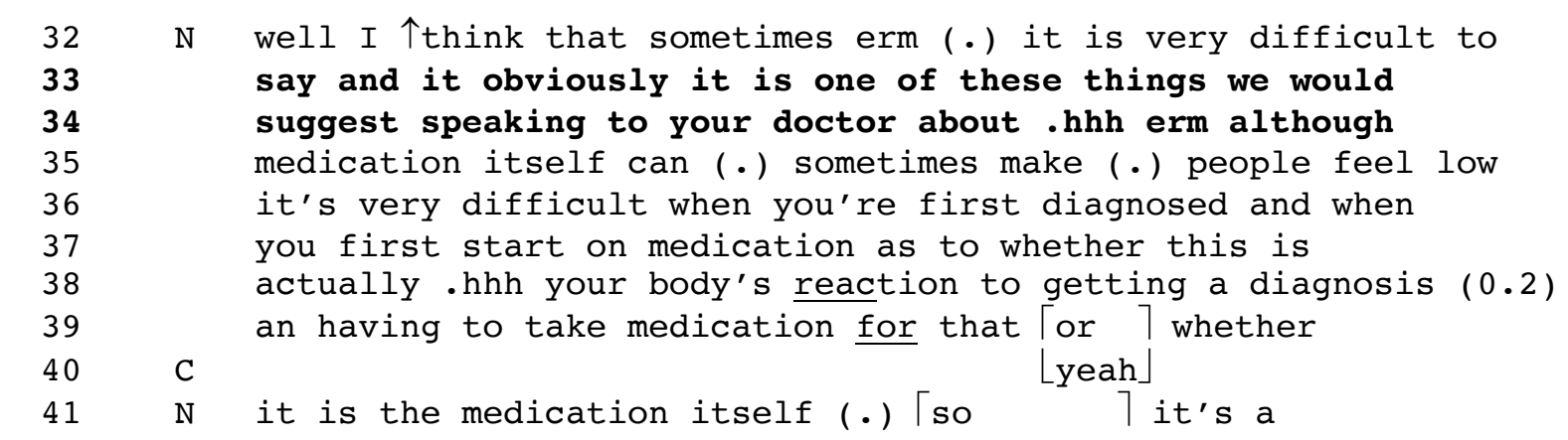

The call-taker's obviously disclaims any personal authority in the course of action that is to come (it is something as it were generally known), which is further removed from the 
particularities of the case by referring to it as an example of a class of unspecified events (things). The action is then further minimised by being cast contingently with the modal verb would. The call-taker does still further low-deontic work (by claiming the difficulty of certainty, in lines 32 and in lines 36 onwards), but it is these features that make her recommendations safely generic.

It is perhaps helpful to see that in spite of the obliqueness of this practice, the caller does understand it as advice. Example 10 shows the caller making this explicit.

\section{Example 10}

\section{Parkinson's D550083}

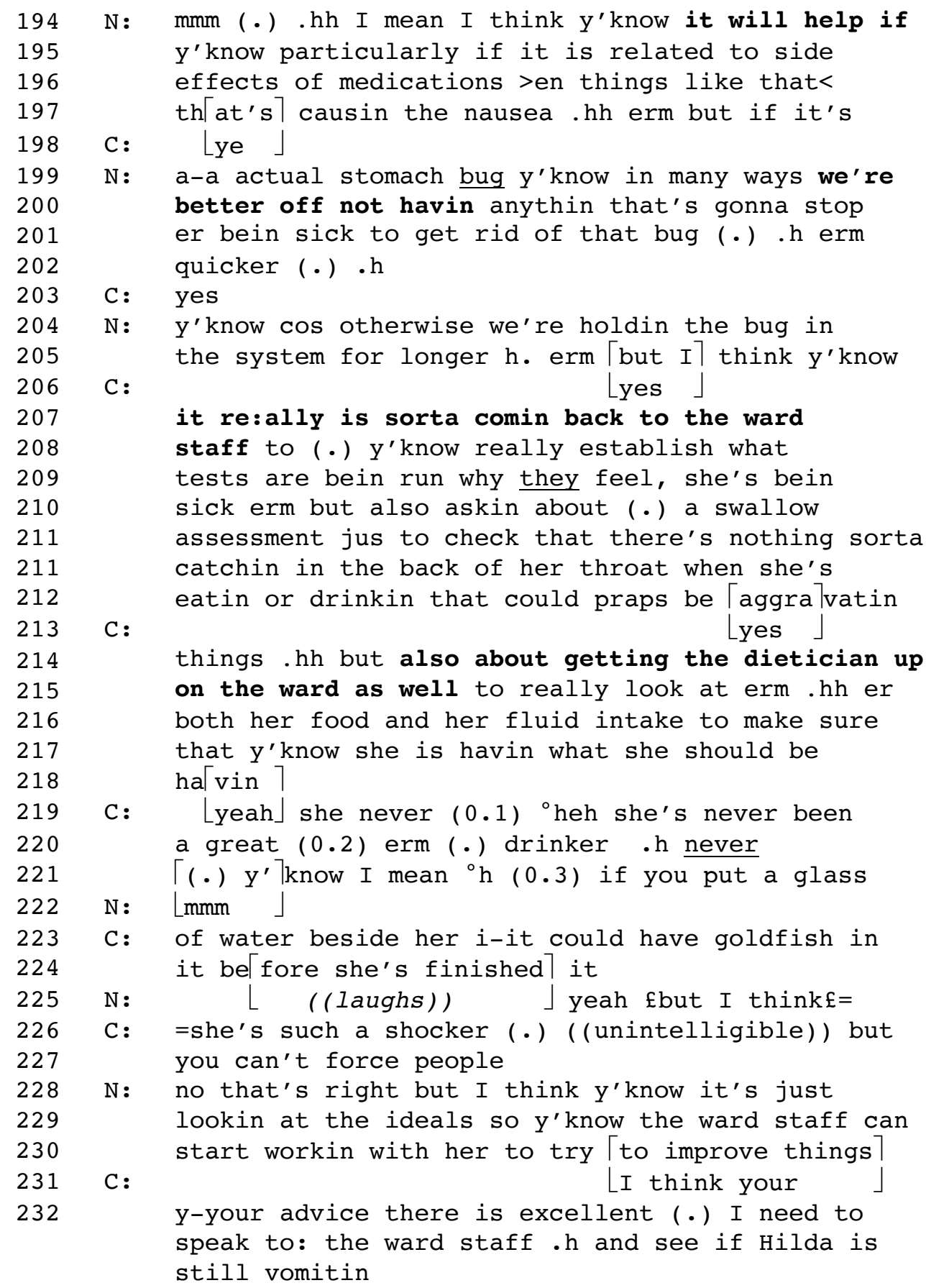


Advising by reporting in-principle courses of action, then, shares with contingent advice the dual benefits (to the call-taker) of manifestly not giving advice, and also distancing the information from the caller's epistemic domain - it is she, the call-taker, who has access to general medical knowledge, precedent, institutional arrangements and so on. The caller doesn't, so it makes any challenge they might want to issue, or any return to their particulars they want to propose, more interactionally difficult.

Difficult, but of course not impossible. Shaw and Kitzinger 's article is largely devoted to an analysis of how the caller resists, over about eight minutes, the call-taker's (in their case, non-medical) advice, by dint of a catalogue of specific details about her particular situation. As they say: "the call-taker's commitment to 'moving on' to the solution ... conflicts with Petra's [the caller's] commitment to troubles-talk" (2013, p. 17). It is worth detailing a case from the Parkinson's data that illustrates this more fully, in a necessarily rather long extract. The caller is worried teaching swimming to someone with Parkinson's; as it happens, it also turns out that the caller's father has motor neurone disease (see line 121-122), and this seems to fuel, or licence, the non-uptake of the call-taker's advice.

Example 11

Parkinson's D5500103

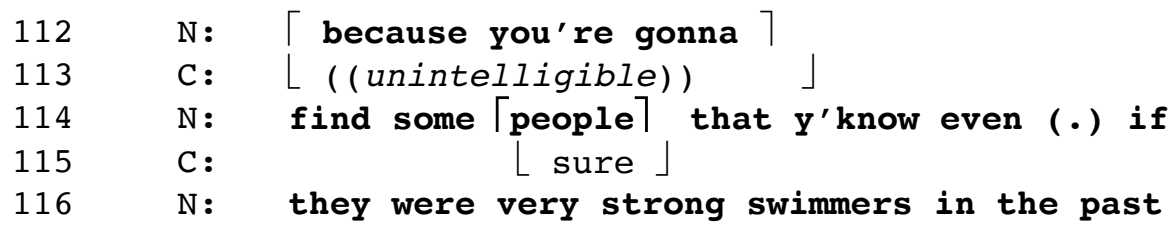

$117 \quad \mathrm{~N}$ : erm may that

118 「find that they have difficulties $\rceil$ now in

C : ((unintelligible))

the water $\left\lceil{ }^{\circ} \mathrm{h}\right.$ erm

actually has motor neurones so and he was a very strong er front crawler sortof to county standard and because he has the motor neurones that affects his speech ${ }^{\circ} \mathrm{h}$ we've found now that he really can't put his face in the water and so the normal sortof breathing activity= $\mathrm{N}: \quad=\mathrm{u}\lceil$ huh $\rceil$

C: Lso Jhe's changed his stroke to breast stroke now $\lceil$ so that $\rceil$ he actually holds his

$\mathrm{N}$ : $\quad\lfloor$ yeh $\rfloor$

C: head above the water an the doctors at the rvi are actually really pleased that he's actually doin exercises ${ }^{\circ} \mathrm{h}$ so I've already got sortof invested interest in that but wand I appreciate and know that obviously I I understand ${ }^{\circ} \mathrm{h}$ theres any any kind of er person who's less able ${ }^{\circ} \mathrm{h}$ the rule book of swimming kindof goes out the window if you like=

$\mathrm{N}: \quad=u m h m=$ 
142

143

144

145

146

147

148

149

150

151
C: =because every single person is different and I teach kids with autism and all sorts of things basically and I know from that experi「ence all I $\rceil$ re:ally wanted

$\mathrm{N}:$
$\mathrm{C}: \quad$ to know from your good selves is are there any real do's and don'ts because I've uh obviously read up some things on your website already I haven't done as much as I could $\left\lceil\right.$ do er but I read $y^{\prime}$ know

At line 114 the call taker issues, in the familiar non-specific, in-principle way, the information that some people ... may find that they have difficulties; but the caller nevertheless pursues the details of her own case. She prefaces her pursuit at line 121 affiliative agreement (line 121) yeh yeh yeh but immediately, and when her speech is clear of overlap, issues a no. This may be an affiliative echo of the call-taker's description of the negative effects of Parkinson's but it also introduces a long description of her father's particulars in overcoming those in-principle effects of the disease. We have shown 30 lines to give a flavour of it, but it goes on longer. So although contingency and generic information are designed to make such talk less easy for the caller to produce, they can be resisted.

\section{Contrast cases when the advice is firm and unilateral: managing closings}

It would be a mistake to suggest that only a low deontic stance could advance the institutional and interactional interests of the call-taker. Imperatives and bald injunctions about uncontroversial courses of action are prominent in the call-taker's efforts to manage a positive course of action and also bring the conversation to a close, as the examples below illustrate.

\section{Example 12}

Parkinson's, DS550073

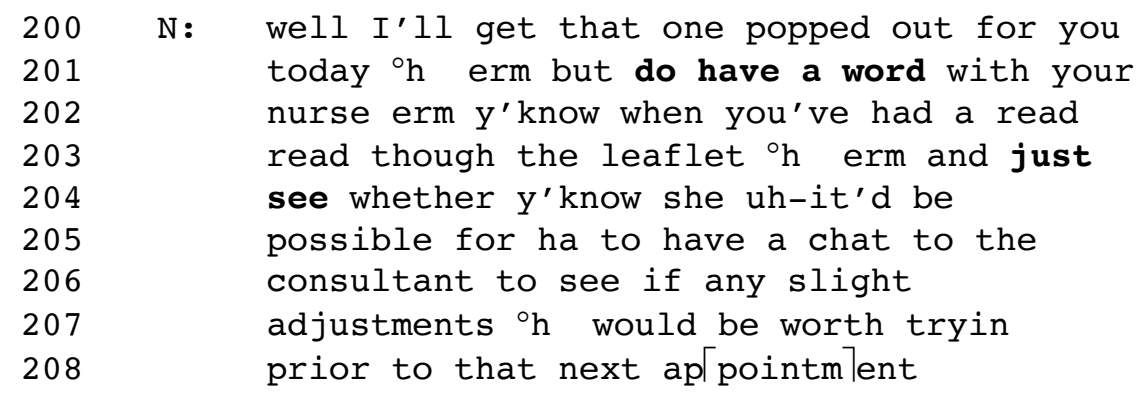

Example 13

Parkinson's DS550069

$\mathrm{N}$ :

Łwell that's」it an I think

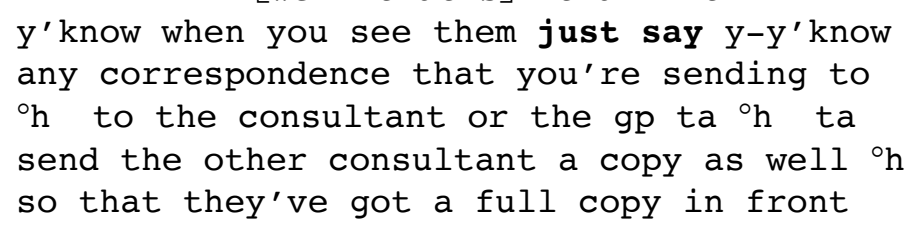


Example 14

Greatbatch et al,2005, p 812, extract 3, part: NHS Direct

In Example 12 the call-taker issues the bald imperatives do have a word and just see, and in Example 13 it is just say, and in 14, just call us back. We can see the two factors at work to allow, or facilitate, such firmness here. One is the nature of the course of action - banal (having a word, copying a document to another recipient), low-effort (just seeing, just saying) or so obvious that it almost goes without saying.

The other element to note is, as we have insisted throughout, the local interactional benefit: here it is making the arrangements which are a conversational signal that closing is about to happen. As we had seen with the contingent, in-principle low-deontic advice for consequential courses of action, these more unrestrained injunctions serve a useful interactional purpose. Making arrangements is, as described right at the start of the CA account of conversation (see Schegloff and Sacks, 1973, and developments in Button, 1987; perhaps most especially, arrangements in closing the medical encounter in White et al, 1997), part of the close-down sequence (the importance of which for patient satisfaction is shown by Woods et al, 2015) preparing participants for terminating the encounter. This is especially salient for a call-taker, who must bring the encounter to a close while also orienting to the caller's expressed needs: by instructing the caller to make banal and lowcost 'arrangements', the call-taker elegantly meets both objectives.

\section{Discussion}

We set out to expand our understanding of how a medical helpline call-taker might manage the dilemma of satisfying the caller's needs, while avoiding giving advice that, even if qualified, they were institutionally mandated not to give. We based the study on what was already known about advice-giving helplines, where the call-taker was not qualified to give medical advice (a child health line, Butler et al 2009, and a home-birth helpline, Shaw and Kitzinger, 2013), with helpful contrastive background in a medical helpline where the calltaker was in fact expert enough to give advice (the NHS Direct telephone service, analysed by Greatbatch et al, 2005).

By looking at a new set of calls (from the Parkinson's UK helpline) we confirmed a known practice (treating the problem as one not requiring a new course of action) and identified three more - advice-as-information (familiar from Silverman and Peräkylä, 1990), advising contingently, and advising in principle. Our interest was in finding features that would be common to all the data. We argued that we could set the old and the new practices under the general umbrella of deontic stance - that is, the call-taker's care in presenting the course of action in a way that presumed less authority to instruct the caller ${ }^{6}$, and which put some

\footnotetext{
${ }^{6}$ It is worth noting that there was one practice described by Butler et al that we left to one side in our catalogue: deferring to the caller's status as the child's parent. We can see now in retrospect that even this
} 
distance between the generality of the course of action and the specificity of the caller's particular situation. This is very different from the kind of practice generally found in interactions between someone with explicitly medical qualifications (a general practitioner, a consultant and so on) who, though they may hedge in various ways as amply described in the Special Issue of Human Communication edited by Stivers and Barnes (see their introductory article, Stivers and Barnes, 2018), nevertheless deliver recommendations based on their categorical medical authority.

In the kind of interaction we've studied here, we noted, as had previous studies, that the call-taker's avoided giving advice on inadequate evidence, in line with the their institutional mandate. But we added a new observation: that they also served the subtler interactional need to maintain an onward sequence of exchanges in the smoothest possible way, and to lead (as the call-taker's task demanded) to a satisfactory termination of the call. Disclaiming expertise, and putting the course of action at a general level, safely distant from the particularities of the caller's circumstances, were ways of avoiding getting embroiled in the details of their situation - although as we saw in Example 11, it is always available to the caller to find some way of tropicalising their problem anew. Nevertheless, positive, if contingent and general, advice limits that freedom, and avoids a to- and fro- that would only, in the end, lead to the same consequence of non-specific advice.

Call-takers on these lines have to weigh up the medical, legal and professional obligations of the risks associated with giving what might be bad advice. But this is perhaps a special case of any service encounter where some kind of constraint, experienced as unhelpful by the service-user, operates on the provider. It will be a matter of enquiry to see if the deontic scale- the lower end of contingent and in-principle formulations for substantial advice, and the higher end for the trivial - captures at least some of the practices that any call-taker may use. We may perhaps give just one example where the fit seems plausible. In telephone advice conversations between debt advisors and individuals in debt, reported by Andelic et al, (2018), expert call-takers have licence to offer callers information on loan repayments, and the extracts given in the article show the familiar mix. We see the call-taker using highdeontic imperatives for local management of the interaction: for example, in reply to their client saying I can't stop feeling really guilty like I'm doing something really wrong, the calltaker responds with It's - listen, just remove all emotion from this because believe me [Client's name] they ((i.e. the creditors)) will (Andelic et al 2018, p 637). But when it comes to substantial advice, another extract shows the call-taker advising the client not to include certain items in their proposed repayment budget, the instruction becomes contingent and in-principle: we wouldn't be allowed to set aside twenty-five pounds for take-away [meals] and monthly for getting our eyelashes and eyebrows done, and the creditors would see those as ehm (...) as luxuries really.

Where the service places strict requirements on the caller (as does any telephone service that deals with emergencies), then perhaps the kind of discreet practices we've seen here are unnecessary, and the call-taker may have greater entitlement to use outright instruction

falls neatly under the umbrella of low deontic entitlement. When the call-taker says, for example, well, I guess um sort'v ye-again you'd have to go on your gut instinct there ( $\mathrm{p} 826$, transcription much simplified), she is passing responsibility from herself to the parent. 
at the higher end of the deontic scale. The UK's 999 or the USA 's 911 emergency lines, for example, place a high premium on the nature of the caller's problem and request. If a call qualifies as a medical emergency, for example a report of an injured person, then instruction will be given unilaterally and imperatively (e.g. of how to stop the bleeding, what position to put the patient in, and so on), whereas problems deemed inappropriate will get short shrift (see for example, the failed "riddle" call reported in Raymond and Zimmerman, 2016, or Kent and Antaki 2019, for illustrations of brusque dismissal of inappropriate calls to the UK's 999 service). So the scope and strength of instruction available to the call-taker will be at least in part determined by the nature of the urgency and significance of the helpline's service, and the authority that that imparts to the call-taker. But outside of the emergency services, call-takers on 'softer' helplines, who need to operate at the deontically less imposing end of the scale, will use contingent, in-principle advice to manage their dilemma of satisfying the client while also working within their mandated limits and keeping the interaction on track. For call-takers on such services, where a need to respond to urgency gives way to a mandate to offer support, the call-taker must balance relieving the client's anxieties against promising more than the service can, or should, deliver.

Address for correspondence

Charles Antaki

School of Social Sciences and Humanities

Loughborough University

Loughborough LE11 3TU

UK

c.antaki@Lboro.ac.uk 


\section{References}

Andelic, N., Stevenson, C., \& Feeney, A. (2019). Managing a moral identity in debt advice conversations. British Journal of Social Psychology, 58(3), 630-648.

Antaki, C., \& Kent, A. (2012). Telling people what to do (and, sometimes, why): Contingency, entitlement and explanation in staff requests to adults with intellectual impairments. Journal of Pragmatics, 44(6-7), 876-889.

Baker, C., Emmison, M., \& Firth, A. (Eds.). (2005). Calling for help: language and social interaction in telephone helplines. John Benjamins Publishing.

Bloch, S., \& Antaki, C. (2019). The Pivot Point between Problem Presentation and Advice in a Health Helpline Service. Applied Linguistics, 40(4), 699-716,

Bloch, S., \& Leydon, G. (2019). Conversation analysis and telephone helplines for health and illness: A narrative review. Research on Language and Social Interaction, 52 (3), 193211.

Brown, P. \& Levinson, S. C. (1987). Politeness: Some universals in language usage. Cambridge" Cambridge University Press.

Butler, C. W., Danby, S., Emmison, M., \& Thorpe, K. (2009). Managing medical advice seeking in calls to Child Health Line. Sociology of health \& illness, 31(6), 817-834.

Butler, C., Danby, S., \& Emmison, M. (2015). Avoiding giving advice in telephone counselling for children and young people. In F. H. . Chevalier \& J. Moore (Eds.), Producing and Managing Restricted Activities: Avoidance and withholding in institutional interaction (pp. 83-114). John Benjamins.

Butler, C. W., Potter, J., Danby, S., Emmison, M., \& Hepburn, A. (2010). Advice-implicative interrogatives: Building "client-centered" support in a children's helpline. Social Psychology Quarterly, 73(3), 265-287.

Button, G. (1987). Moving out of closings. In G. Button, \& J.R. E. Lee (Eds.),Talk and social organisation(pp. 101-151).Clevedon: Multilingual Matters.

Craven, A., \& Potter, J. (2010). Directives: Entitlement and contingency in action. Discourse Studies, 12(4), 419-442.

Dingemanse, M. (2020). Between sound and speech: Liminal signs in interaction Research on Language and Social Interaction, 53, 188-196

Garcia, A. C. (2012). Advice-giving and disputant empowerment in divorce mediation sessions. Language and Dialogue, 2(3), 398-426. 
Greatbatch, D., Hanlon, G., Goode, J., O'Caithain, A., Strangleman, T. and Luff, D. (2005) Telephone triage, expert systems and clinical expertise, Sociology of Health and IIIness, $27,6,802-30$.

Hepburn, A., \& Potter, J. (2007). Crying Receipts: Time, Empathy, and Institutional Practice. Research on Language and Social Interaction, 40, 89-116

Heritage, J., \& Lindström, A. (2012). Advice giving-terminable and interminable: The case of British health visitors. Advice in discourse, 169-193.

Heritage, J., \& Raymond, G. (2005). The terms of agreement: Indexing epistemic authority and subordination in talk-in-interaction. Social psychology quarterly, 68(1), 15-38.

Jefferson, G. (2004). Glossary of transcript symbols with an introduction. In G. H. Lerner (Ed). Conversation Analysis: Studies from the First Generation. (pp: 13-31). Amsterdam: John Benjamins.

Keevallik, L., \& Ogden, R. (2020). Sounds on the margins of language, at the heart of interaction. Research on Language and Social Interaction, 53, 1-18

Kendrick, K. H., \& Drew, P. (2016). Recruitment: Offers, requests, and the organization of assistance in interaction. Research on Language and Social Interaction, 49(1), 1-19.

Landqvist, H. (2005). Constructing and negotiating advice in calls to a poison information centre. In C. Baker, M. Emmison, \& A. Firth (Eds.), Calling for help : language and social interaction in telephone helplines (pp. 207-234). Amsterdam: John Benjamins

Leppänen, V. (1998) The straightforwardness of advice: advice-giving in interactions between Swedish district nurses and patients, Research on Language and Social Interaction, 31, 209-39.

National Health Service (no date) NHS 111 https://www.nhs.uk/using-the-nhs/nhsservices/urgent-and-emergency-care/nhs-111/ (accessed 10 December 2019)

National Society for the Prevention of Cruelty to Children (no date) https://www.nspcc.org.uk (accessed 10 December 2019)

Pilnick, A. (1999) Patient counselling by pharmacists: Advice, Information or Instruction? The Sociological Quarterly, 40, 4, 613-22.

Raymond, G., \& Zimmerman, D. H. (2016). Closing matters: Alignment and misalignment in sequence and call closings in institutional interaction. Discourse Studies, 18(6), 716736.

Royal College of Nursing. (2006). Telephone advice lines for people with long term conditions: Guidance for nursing practitioners. London: Royal College of Nursing. 
Schegloff, E. A., \& Sacks, H. (1973). Opening up closings. Semiotica, 8(4), 289-327.

Shaw, R., \& Kitzinger, C. (2013). Managing Distress, Effecting Empowerment: A Conversation Analytic Case Study of a Call to the Home Birth Helpline. International Review of Social Research, 3, 7-28. doi.10.1515/irsr-2013-0008

Silverman, D., \& Peräkylä, A. (1990). AIDS counselling: the interactional organisation of talk about 'delicate' issues. Sociology of Health \& IIIness, 12(3), 293-318.

Stevanovic, M., \& Peräkylä, A. (2012) Deontic authority in interaction: The right to announce, propose, and decide, Research on Language \& Social Interaction, vol. 45, no.3), pp. 297-321.

Stivers, T., and Barnes, R. K. (2018) Treatment Recommendation Actions, Contingencies, and Responses: An Introduction Health communication, 1331-1334.

Stivers, T., Heritage, J., Barnes, R. K., McCabe, R., Thompson, L., \& Toerien, M. (2018). Treatment recommendations as actions. Health communication, 33(11), 1335-1344.

Stommel, W., \& Molder, H. te. (2018). Empathically designed responses as a gateway to advice in Dutch counseling calls. Discourse Studies, 20, 523-543.

Waring, H. Z. (2017). Going general as a resource for doing advising in post-observation conferences in teacher training. Journal of Pragmatics, 110, 20-33.

White, J., Rosson, C., Christensen, J., Hart, R., \& Levinson, W. (1997). Wrapping things up: A qualitative analysis of the closing moments of the medical visit. Patient Education andCounselling,30, 155-165

Woods, C. J., Drew, P., \& Leydon, G. M. (2015). Closing calls to a cancer helpline: Expressions of caller satisfaction. Patient education and counseling, 98(8), 943-953. 